\title{
Reverse Flow Sural Flap Coverage in Sequel of Electric Burn, Case Report
}

\author{
Bastidas Mauro, ${ }^{1}$ Pacheco Federico, ${ }^{2}$ Velasco Jonathan ${ }^{2 *}$ \\ ${ }^{1}$ Médico Tratante. Servicio de Cirugía Plástica, Reconstructiva y Estética. Unidad de Quemados. Hospital Especialidades Eugenio Espejo. Quito - Ecuador. \\ ${ }^{2}$ Médico Residente. Servicio de Cirugía Plástica, Reconstructiva y Estética. Unidad de Quemados. Hospital Especialidades Eugenio Espejo. Quito - Ecuador.
}

\begin{abstract}
Reconstruction of injuries and defects in the distal third of the lower extremities represents a challenge for the plastic surgeon. The clinical case of a 46-year-old patient with a sequela of electrical burn in the distal third of the leg and the proximal third of the right foot is presented, who underwent skin coverage with a reverse flow sural flap. The treatment performed is described, as well as the surgical technique. We consider that the reverse flow sural flap is an optimal option when evaluating different forms of coverage in lesions of the distal third of the lower extremities, with positive long-term results.
\end{abstract}

Keywords: Electrical burn, Reconstructive surgery, Sural flap

\section{Introduction}

The repair of injuries and defects of the lower limb located in its distal third constitutes a challenge for reconstructive plastic surgery. The research reflected in different bibliographic sources has allowed us to know a variety of procedures to perform the cutaneous coverage of this region, being a great alternative for this defect the reverse flow sural flap. ${ }^{1}$ Among the most common causes of lower limb defects are high voltage electrical burns (greater than 1000 volts), along with other high-impact traumatic causes, which can lead to death and/or amputation of extremities. ${ }^{2}$ In an electrical burn, the increased resistance of the bone tissue to the electrical current generates heat and in the most distal region of the extremities, vasoconstriction, thrombosis and progressive ischemic necrosis occur that injure the surrounding muscle tissue, which can cause large defects that are difficult to cover. ${ }^{3}$ The closure of these defects, caused by an electrical burn, implies a difficulty when selecting the appropriate treatment, since skin grafts are not a reconstructive option, taking into account that the vascular bed of the recipient area in this region is often inadequate, in addition to the need to cover other structures such as: tendons and/or muscles, ${ }^{4}$ while the perforator flaps of the leg become a better option when it comes to providing coverage, acting at the level of the same member without generating morbidity in another donor area. ${ }^{5}$ The objective of this work is to present the clinical case of a patient with a defect in his left lower limb, as a result of a high voltage electrical burn, and how this area was covered using the technique of a reverse flow sural flap.

\section{Clinical Case}

A 46-year-old male patient, with no significant pathological history and no surgical history, who, while performing construction work, suffered an electrical burn from direct contact with high-voltage electrical wiring. The physical examination shows his right hand as an entry point and his right foot as an apparent exit point. Patient does not suffer secondary trauma according to paramedical personnel who transferred the patient to our health home, patient is admitted to emergency service where he remains in continuous monitoring for 24 hours, after which he is admitted to the burn unit, where during his hospitalization, several advanced cures and surgical cleanings (mechanical, surgical and enzymatic debridement) were performed until the burn area was delimited. After approximately 25 days of hospital stay, significant soft tissue damage was evidenced in the distal third of the left lower limb, at the level of the anterior face, with exposure of devitalized muscle and tendon tissue. Which were removed, tissue samples were sent for bacterial growth culture, after obtaining negative bacterial growth results, a suitable bed for coverage was prepared for skin coverage, a reverse

\begin{tabular}{|l|l|}
\hline \hline Quick Response Code: & *Corresponding author: Velasco Jonathan. Médico Residente. Servicio de Cirugía Plástica, \\
Reconstructiva y Estética. Unidad de Quemados. Hospital Especialidades Eugenio Espejo. \\
Quito - Ecuador \\
Received: 03 March, 2021 \\
Citation: Bastidas M, Pacheco F, Velasco J. Reverse Flow Sural Flap Coverage in Sequel of Elec- \\
tric Burn, Case Report. SOJ Ortho Rehab. 2021;1(1):1-3. DOI: \\
10.53902/SOJOR.2021.01.000502
\end{tabular}


flow sural flap was performed in the distal third of our patient's lower limb (Figure 1).
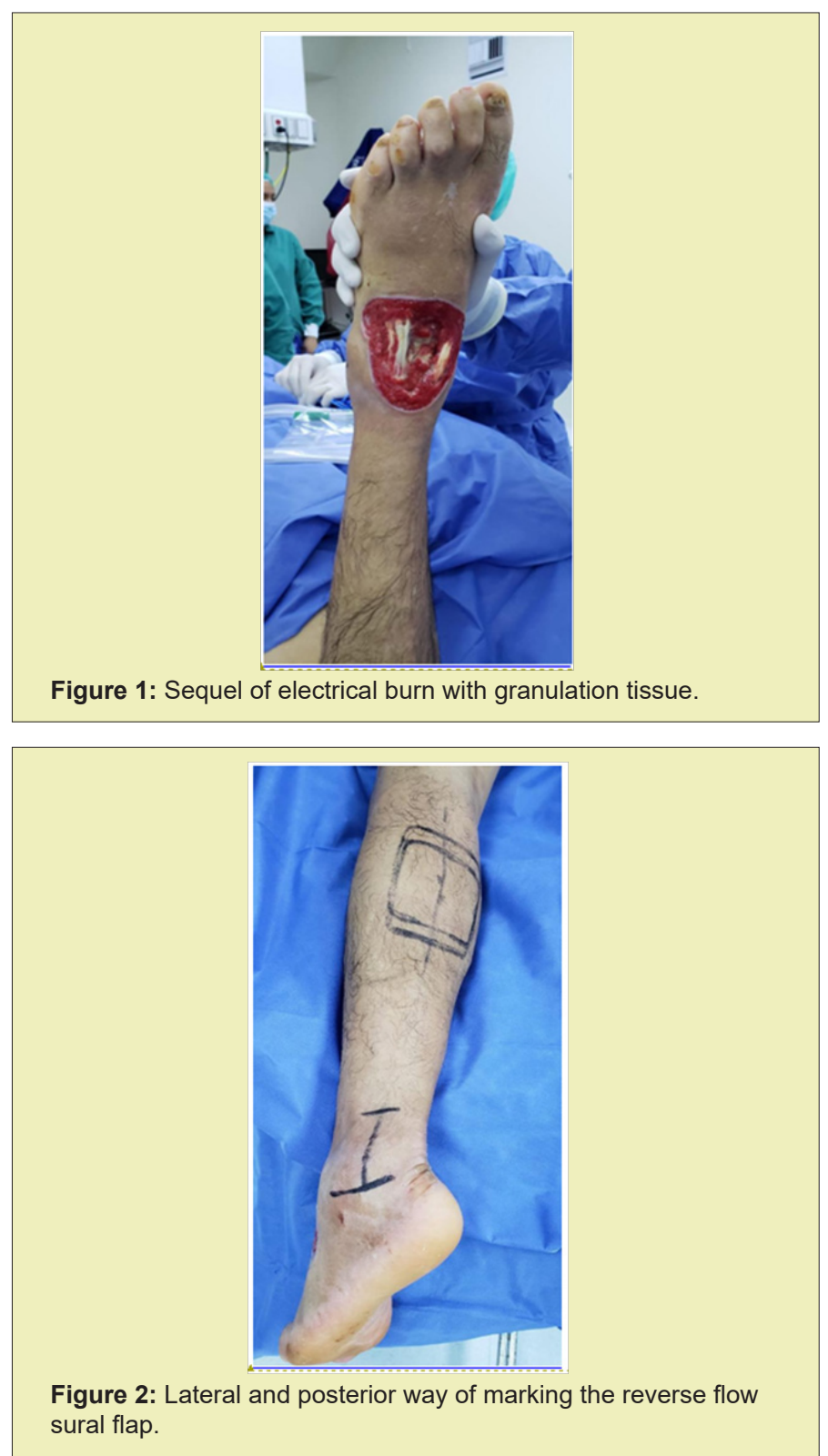

Complete defect is circumferential $6 \times 6 \mathrm{~cm}$. The patient was placed in the prone position. The flow of the popliteal artery was identified using Doppler echo and between 2 to 5 perforators were found along the intermuscular septum. A line was drawn from the popliteal fossa between the two heads of the gastrocnemius muscles to the lateral malleolus to approximate the vascular axis of the flap, the pivot point of the flap was marked $5 \mathrm{~cm}$ above the tip of the lateral malleolus (Figure 2). The size of the flap was defined using the defect template already taken after debridement of the wound. The length of the pedicle was sufficient to allow access to the defect and preserve the proximal quarter (below the popliteal crease) of the back of the leg. The dimensions of the flap were $6 \times 6 \mathrm{~cm}^{2}$. To obtain the flap, anincision is made through the skin and fascia along the upper edge of the flap (Figure 3). The vascular pedicle that included the cutaneous median sural nerve, short saphenous vein, and accompanying median superficial sural artery were divided, proximally ligated, and their distal continuations embedded within the flap, the pedicle was then exposed distally, and the skin between the skin island and the chosen pivot point, it was separated in the subcutaneous plane along the entire length of the pedicle. A subcutaneous adipo-fascial pedicle of at least $3 \mathrm{~cm}$ wide was maintained to preserve its vascularization. The skin island as well as the pedicle were elevated from proximal to distal in the sub-fascial plane to the chosen pivot point and then the skin island was passed through a wide subcutaneous canal into the defect, without kinks to allow transposition of the pedicle and the flap was inserted (Figure 4). Finally, the skin of the donor site was closed as much as possible and the remaining open wound at the donor site was covered with partial thickness skin graft (Figure 5).

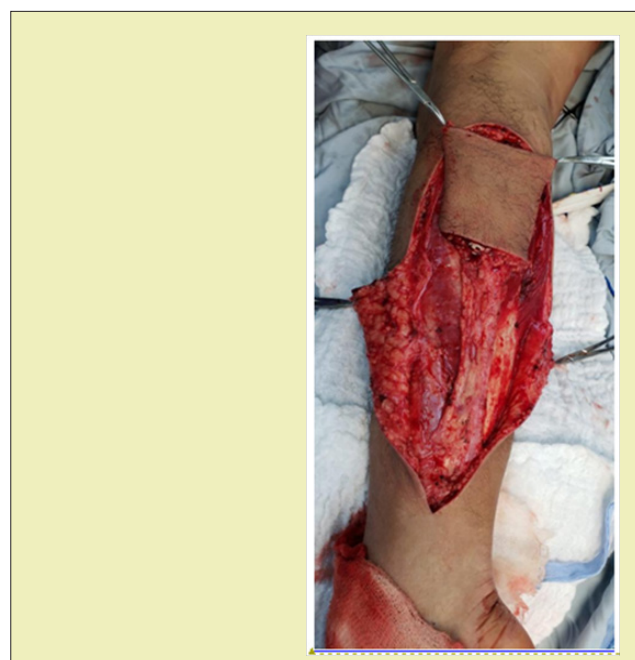

Figure 3: The flap is lifted from proximal to distal, trying to lift the vascular pedicle and expose the muscle fibers of the gastronecmus muscle.

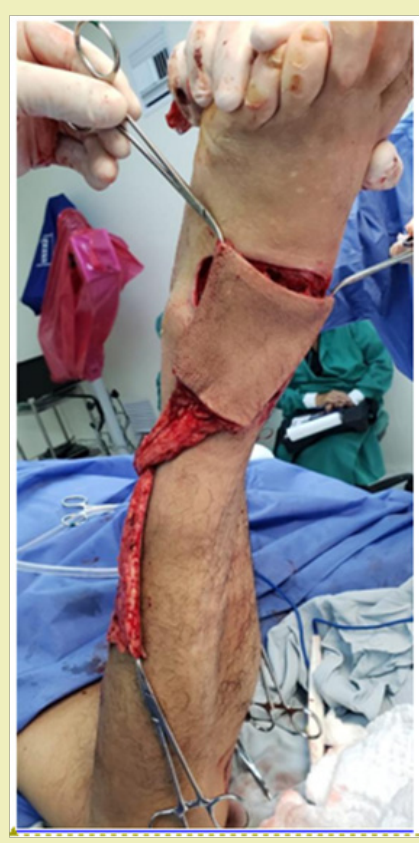

Figure 4: Raised sural flap with its pedicle contained in the subcutaneous cellular tissue. 


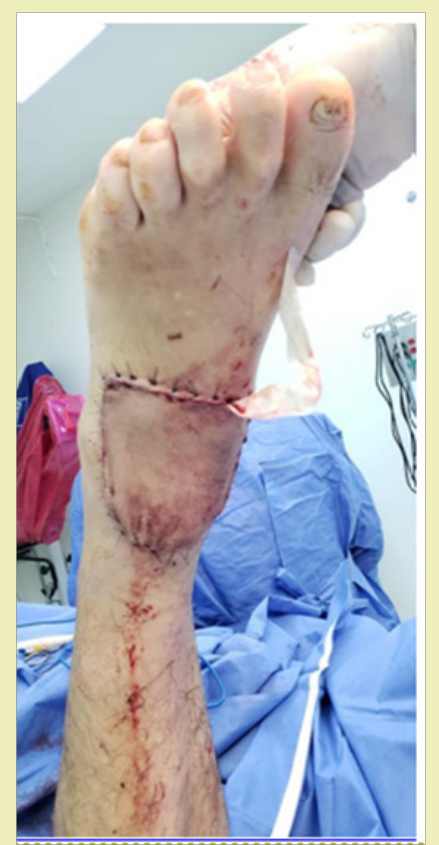

Figure 5: Complete coverage of the defect with the reverse flow sural flap.

The patient remained hospitalized for 21 postoperative days until the vitality and viability of the flap was verified (color, capillary filling and temperature). During this time, he continued with periodic healing, positional measurements, and use of a bower. Subsequently, the patient was discharged from hospital and controls were maintained by outpatient consultation, evidencing the good condition of the sural flap (Figure 6).

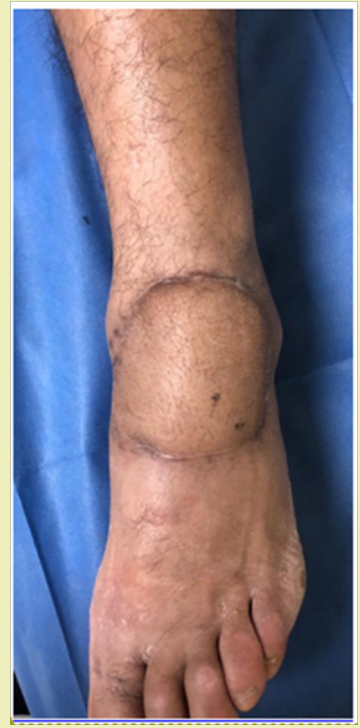

Figure 6: Control at 3 months.

\section{Discussion}

Defects in the distal lower limb are usually cases of difficult management, representing a high degree of difficulty when it comes to their reconstructive solution, with the main objective being to maintain a functional limb. ${ }^{6}$ It must be taken into account that the choice of the local flap is limited due to inadequate local tissue for reconstruction and poor circulation. ${ }^{7}$ That is why we decided to use a reverse flow sural flap, the same as because it has a robust and reliable vascular perfusion at the distal level, since at this level it is irrigated by various blood sources, which helps to maintain the viability of the flap. ${ }^{8}$ Lately there has been a preference for free tissue transfer, however local pedicle flaps remain a valuable option. The advent of perforator pedicle flaps, the reverse sural artery flap has become less popular but should be considered as a legitimate and

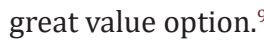

\section{Conclusion}

The reverse flow sural flap is safe, reliable and durable as a coverage option for defects of the distal third of the lower limb of different etiologies, ${ }^{2}$ in the case of our patient it represented an adequate and effective form of coverage for a defect caused by the electrical current to level of distal third of lower limb. Being its simple and easily executable surgical technique in a surgical room. We consider that the reverse flow sural flap is an optimal option when evaluating different forms of coverage, with positive long-term results as long as there is correct follow-up and the patient starts with immediate and mediate postoperative self-care.

\section{Acknowledgments}

None.

\section{Funding}

None.

\section{Conflicts of interest}

Author declares that there is no conflict of interest.

\section{References}

1. Barrios J, Sandoval J, Méndez E, et al. Use of the sural flap for the reparation of defects in the lower member: Rescue of a limb. Cirugia Paraguaya. 2019;43(1):38-40.

2. Eser C. An alternative method to free flap for distal leg and foot defects due to electrical burn injury: distally based cross-Leg Sural Flap. TurkJ Trauma Emerg Surg. 2015.

3. Martínez S, Perroni NC, Nacir SR, et al. Lower limb reconstruction after electrical burn evolved with bilateral.

4. Peralta Jerezano A, Abductor digiti minimi flap, a current option in soft tissue reconstruction of the foot. Cirugía Plástica Ibero-Latinoamericana. 2016;42(3):5.

5. Carabelli G, Barla JD, Taype DR, et al. Fasciocutaneous sural flap for softtissue coverage in the third distal leg, ankle and foot. Clinical Research. 2017;82(2):136.

6. Saaiq M,Zimri Fuk. Reverse FlowSuperficial Sural Artery Fasciocutaneous Flap: A Comparison Of Outcome Between Interpolated Flap Design Versus Islanded Flap Design. World J Plast Surg. 2019 Sep;8(3):316-323.

7. Tan O, Atik B, Bekerecioglu M. Supercharged Reverse-Flow Sural Flap: A new modification increasing the reliability of the flap. Microsurgery. 2005;25(1):36-43.

8. Sugg KB, Schaub TA, Concannon MJ, et al. The Reverse Superficial Sural Artery Flap Revisited For Complex Lower Extremity And Foot Reconstruction. Plastreconstr Surg Glob Open. 2015;3(9).

9. Schmidt K, Jakubietz M, Djalek S, et al. The Distally Based Adipofascial Sural Artery Flap: Faster, Safer, And Easier? A Long-Term Comparison of the Fasciocutaneous and Adipofascial Method in A Multimorbid Patient Population. Plastreconstr Surg. 2012;130(2):360-368. 